\title{
An experimental investigation on the airside performance of fin-and-tube heat exchangers having corrugated louver fins - Part I; dry surface
}

\author{
Nae-Hyun KIM* \\ *Division of Mechanical System Engineering, Incheon National University \\ 12-1 Songdo-Dong, Yeonsu-Gu, Incheon 406-772, Korea \\ E-mail: knh0001@inu.ac.kr
}

Received: 26 November 2019; Revised: 28 January 2020; Accepted: 20 February 2020

\begin{abstract}
Corrugated louver fin, which has louvers on wavy surface, may be a promising mean to augment the air-side heat transfer of fin-and-tube heat exchangers. However, only limited prior studies are available. In this study, two kinds of corrugated louver fin-and-tube heat exchangers - one having one corrugation per row and the other having two corrugations per row - were tested, and the results were compared with those of the standard louver fin and the plain fin samples. The highest $j$ and $f$ factor were obtained for the standard louver fin sample, followed by the single corrugated louver fin, the double corrugated inclined louver fin and then the plain fin sample. The high $j$ and $f$ factor of the standard louver fin sample may be due to the large louver fraction on the fin surface. Furthermore, larger fin surface area of the double corrugated louver fin compared with that of the single corrugated fin may be the reason for the smaller $j$ and $f$ factor. All the enhanced fin samples yielded larger heat transfer capacity than the plain fin sample at the same pumping power. Furthermore, the largest heat transfer capacity per pumping power was obtained for the standard louver fin sample. The single corrugated louver fin sample yielded higher heat transfer capacity per pumping power than the double corrugated sample.
\end{abstract}

Keywords : Heat exchanger, Heat transfer coefficient, Pressure drop, Fin, Corrugated, Louver, Dry

\section{Nomenclature}

$A$

$A_{c}$

$A_{l}$

$A_{m}$

$A_{t}$

$C$

$c_{p}$

$D$

$D_{h}$

$f$

G

$h$

$j$

$k$

$L$

$L_{p}$

$n_{l}$

heat transfer area, $\mathrm{m}^{2}$

minimum free flow area, $\mathrm{m}^{2}$

louver area, $\mathrm{m}^{2}$

heat transfer area at the middle plane of tube wall, $\mathrm{m}^{2}$

heat transfer area of the tube, $\mathrm{m}^{2}$

heat capacity, W/K

specific heat, $\mathrm{J} / \mathrm{kgK}$

tube diameter including fin collar thickness, $\mathrm{m}$

hydraulic diameter $\left(=4 L A_{d} / A\right), \mathrm{m}$

friction factor

mass flux, $\mathrm{kg} / \mathrm{m}^{2} \mathrm{~s}$

heat transfer coefficient, $\mathrm{W} / \mathrm{m}^{2} \mathrm{~K}$

Colburn $\mathrm{j}$ factor

thermal conductivity of the tube, $\mathrm{W} / \mathrm{mK}$

heat exchanger length, $\mathrm{m}$

louver pitch, $\mathrm{m}$

number of louvers 

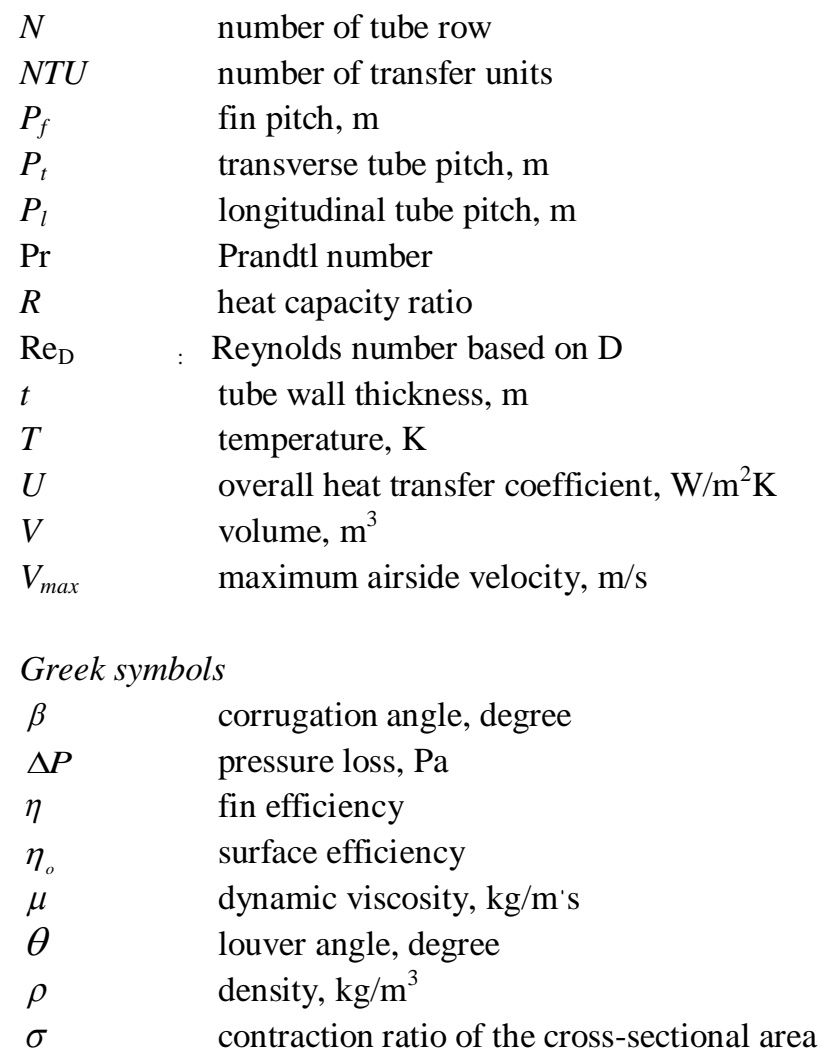

$\begin{array}{ll}\text { Subscripts } & \\ \mathrm{a} & \text { air } \\ \text { exp } & \text { experimental } \\ \mathrm{i} & \text { tube-side } \\ \text { in } & \text { inlet } \\ \mathrm{f} & \text { fin } \\ \mathrm{m} & \text { mean } \\ \mathrm{o} & \text { airside } \\ \mathrm{p} & \text { plain, pipe } \\ \text { pred } & \text { prediction } \\ \text { out } & \text { outlet } \\ \mathrm{t} & \text { tube }\end{array}$

\section{Introduction}

Fin-and-tube heat exchangers have long been used as evaporators or condensers of residential air-conditioners. For evaporators or condensers, the controlling thermal resistance is on the airside, and enhanced fins (wave, louver, slit, etc.) have been used to reduce the thermal resistance [Webb and Kim (2005), Wang (1999)]. Especially louver fins are widely used for residential applications. Figure 1 shows geometric dimensions related with the louver fin.

The literature shows several studies on thermal performances of louver fin-and-tube heat exchangers, which are summarized in Table 1. Wang et al. (1998a) tested louver fin-and-tube heat exchangers having louvers of $2.4 \mathrm{~mm}$ pitch and $36^{\circ}$ angle, and showed that the effect of fin pitch on $j$ and $f$ factor was insignificant. As for number of tube row, its effect on $f$ factor was negligible. However, $j$ factor decreased as number of tube row increased. In a succeeding study, Wang et al. (1999) tested louver fin-and-tube heat exchangers having different louver pitch and louver angle (shown in Table 1), and developed $j$ and $f$ correlations using the data. Recently, Kim (2015) tested louver fin-and-tube heat exchangers having $1.4 \mathrm{~mm}$ louver pitch and $24^{\circ}$ louver angle. He showed that the effect of fin pitch on $j$ and $f$ factor was insignificant. As for the effect of tube row, both $j$ and $f$ factor decreased as the number of tube row increased. This problem was also tackled numerically. Hsieh and Jang (2012) numerially investigated the effect of louver angle, tube diameter and fin pitch on $j$ and $f$ factor. They showed that, as fin pitch 
increased, $f$ factor decreased. However, $j$ factor was not influenced by fin pitch. As number of tube row increased, $j$ factor decreased. However, $f$ factor was not influenced. With the increase of the tube diameter, $f$ factor increased. However, $j$ factor was not influenced. With increase of louver angle, both $j$ and $f$ factor increased. Additional numerical study by Carija et al. (2014) revealed that, as louver angle or number of louvers increased, both $j$ and $f$ factor increased. Recently, Sadeghianjahromi et al. (2018) provided a correlation based on their numerical data.

The foregoing studies were concerned with louvers formed on a plain fin (standard configuration). However, louvers may also be formed on a wave fin as illustrated in Fig. 1. The literature shows two variants - corrugated louver and convex louver. A corrugated louver fin has simliar louver pattern as the standard louver, except that the louvers are formed on wavy surface. On the other hand, for a convex louver fin, half of the louver is folded down to form a convex pattern. The literature shows only limited studies on these complex louver fin-and-tube heat exchangers. Wang et al. (1998b) tested convex louver fin-and-tube heat exchangers having $1.89 \mathrm{~mm}$ louver pitch and $15.5^{\circ}$ louver angle, and compared the results with those of wave fin-and-tube heat exchangers having the corrugation angle of $15.5^{\circ}$. At the fin pitch of $1.21 \mathrm{~mm}$, the convex louver sample yielded approximately $28 \%$ higher $j$ factor and $60 \%$ larger $f$ factor than those of the wave fin sample. Saiz Jarbardo et al. (2006) performed a similar investigation to Wang et al. (1998b) using convex louver fin-and-tube samples having $2.2 \mathrm{~mm}$ louver pitch and $16^{\circ}$ louver angle. Convex louver fin samples yielded higher $j$ and $f$ factors than those of the wave fin samples. Compared with the wave fin sample, $30 \%$ area reduction was reported at the fin pitch of $3.17 \mathrm{~mm}$. As for corrugated louver fin geometry, only one study by T'Jeon et al. (2006) is available. They tested corrugated louver fin samples having $1.0 \mathrm{~mm}$ louver pitch and $20^{\circ}$ louver angle. Comparison of $j$ and $f$ factors with predictions by Wang et al.'s (1998b) convex louver fin correlation was encouraging.
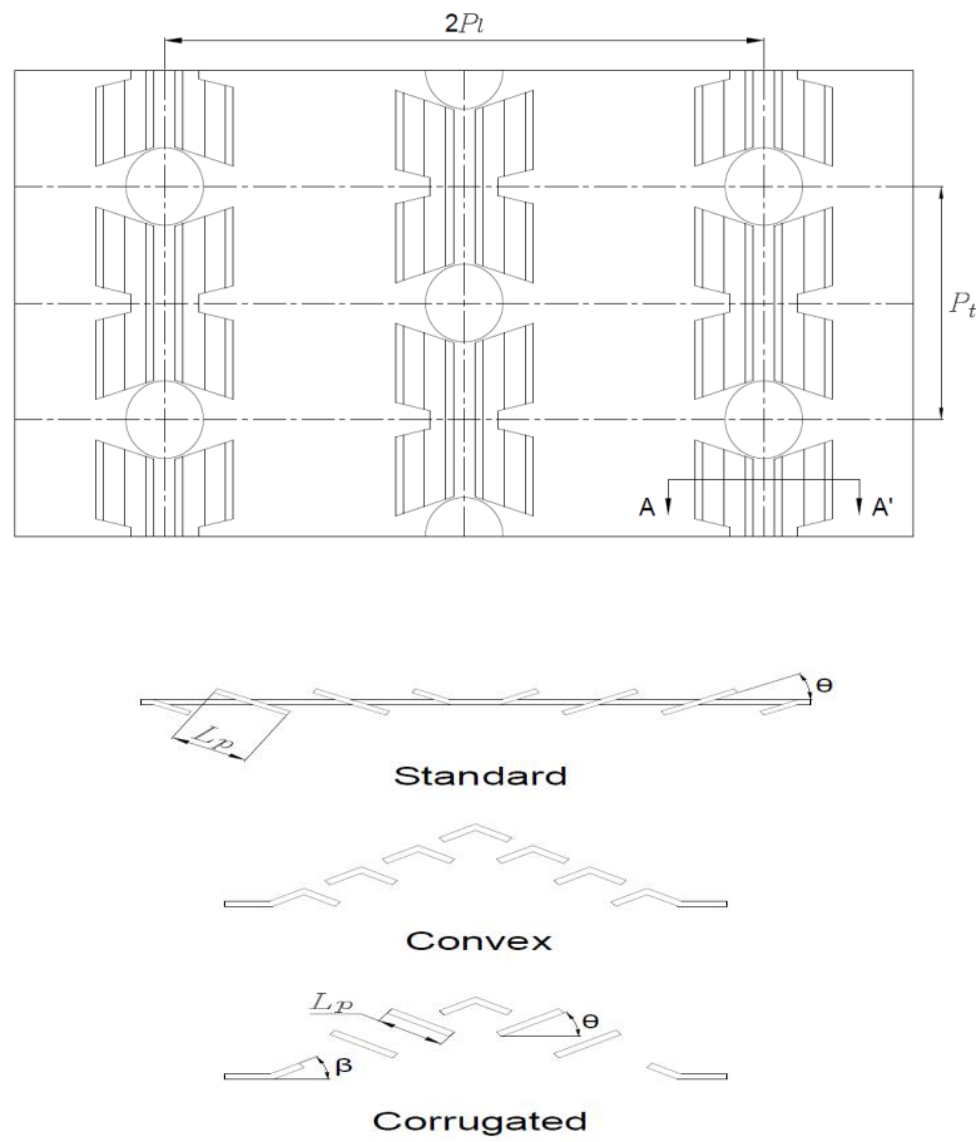

Fig. 1 Geometric dimensions of louver-finned heat exchanger 
Table 1 Previous studies on slit or louver fin-and-tube heat exchangers

\begin{tabular}{|c|c|c|c|c|c|c|c|c|c|c|c|}
\hline Authe & Fin & $\begin{array}{c}L_{p} \\
(\mathrm{~mm})\end{array}$ & $\theta$ & $n_{l}$ & $A_{l} / A_{f}$ & $\begin{array}{c}P_{f} \\
(\mathrm{~mm})\end{array}$ & $\begin{array}{c}P_{t} \\
(\mathrm{~mm})\end{array}$ & $\begin{array}{c}P_{l} \\
(\mathrm{~mm})\end{array}$ & $P_{l} / P_{t}$ & $\begin{array}{c}D \\
(\mathrm{~mm})\end{array}$ & $N$ \\
\hline Wang et al. (1998) & $\mathrm{S}^{*}$ & 2.4 & 36 & 5 & 0.59 & $1.5 \sim 2.08$ & 25.4 & 19.0 & 0.75 & 12.7 & $1 \sim 6$ \\
\hline \multirow{6}{*}{ Wang et al. (1999) } & $\mathrm{S}$ & 2.4 & 36 & 5 & 0.59 & $1.5 \sim 2.08$ & 25.4 & 19.0 & 0.75 & 12.7 & $1 \sim 6$ \\
\hline & $\mathrm{S}$ & 3.75 & 13.5 & 3 & 0.36 & $1.5 \sim 2.1$ & 25.4 & 19.0 & 0.75 & 10.44 & $1 \sim 6$ \\
\hline & $\mathrm{S}$ & 2.35 & 27 & 5 & N/A & $1.21 \sim 2.49$ & 25.4 & 19.05 & 0.75 & 10.3 & 1,2 \\
\hline & $\mathrm{S}$ & 2.0 & 32 & 7 & N/A & $1.21 \sim 2.49$ & 25.4 & 22.0 & 0.87 & 10.3 & 1,2 \\
\hline & $\mathrm{S}$ & 1.7 & 25 & 5 & N/A & $1.22 \sim 1.73$ & 21.0 & 12.7 & 0.6 & 7.53 & 2,4 \\
\hline & $\mathrm{S}$ & 1.7 & 55 & 5 & N/A & $1.20 \sim 1.98$ & 17.7 & 13.6 & 0.77 & 6.93 & 1,2 \\
\hline $\operatorname{Kim}($ & $\mathrm{S}$ & 1.4 & 2 & 5 & 0.335 & $1.3 \sim 1.5$ & 21.0 & 12.7 & 0.6 & 7.3 & $1 \sim 3$ \\
\hline $\begin{array}{l}\text { Hsieh and Jang } \\
\text { (2012) }\end{array}$ & $\mathrm{S}$ & 2.4 & $15 \sim 35$ & 5 & N/A & $1.3 \sim 2.1$ & $18 \sim 30$ & $13 \sim 25$ & N/A & 7.0 12.7 & 1 \\
\hline Carija et al. (2014) & $\mathrm{S}$ & $3.0 \sim 3.75$ & $5=-1$ & 4,5 & $17 / \pi$ & 2.06 & 25.4 & 19.05 & 0.75 & 10.42 & 2 \\
\hline $\begin{array}{l}\text { Sadeghianjahromi et } \\
\text { al. (2018) }\end{array}$ & S & 3.0 & $0 \sim 60$ & 4 & N/A & 3.75 & $25 \sim 40$ & $15 \sim 30$ & N/A & 10.42 & 2 \\
\hline Wang et al. (1998) & $\mathrm{C}$ & 1.89 & 15.5 & 14 & N/A & $1.21 \sim 2.54$ & 25.4 & 19.05 & 0.75 & 8.54 & $1 \sim 4$ \\
\hline $\begin{array}{l}\text { Saiz Jabardo et al. } \\
\text { (2006) }\end{array}$ & $\mathrm{C}$ & 2.2 & 16 & 10 & N/A & 1. & 31.75 & 27.5 & 0.87 & 12.7 & $1 \sim 4$ \\
\hline T'Jeon et al. (2006) & $\mathrm{I}$ & 1.0 & 20 & 6 & N/A & 1.75 & 21.0 & 12.0 & 0.57 & 7.0 & 3 \\
\hline
\end{tabular}

*S : Standard, C: Convex, I: Inclined

The above literature survey reveals that only one study is available for corrugated louver fin geometry, and more investigation on this appears necessary. In this study, two kinds of corrugated louver fin-and-tube heat exchangers - one having one corrugation per row and the other having two corrugations per row - were tested, and the results were compared with those of the standard louver fin samples. This paper deals with dry surface heat transfer and pressure drop characteristics of the corrugated louver fin-and-tube heat exchangers. Wet surface counterpart is available in the accompanying paper (Kim, 2020).

\section{Experiments}

\subsection{Heat exchanger samples}

A total of twelve samples were tested in the present study. They consisted of six single corrugated louver fin samples (1.5, $1.7 \mathrm{~mm}$ fin pitch, 1 3 row) and six double corrugated louver fin samples (1.5, $1.8 \mathrm{~mm}$ fin pitch, 1 3 row). The geometric parameters are listed in Table 2, and detailed dimensions of the corrugated louver fins are illustrated in Fig. 2 along with those of the standard louver fin. The height and the width of the samples were $252 \mathrm{~mm}$ (12 steps) and $400 \mathrm{~mm}$ respectively. The single corrugated louver fin had 8 louvers of $0.92 \mathrm{~mm}$ louver pitch, $33^{\circ}$ louver angle and $10.8^{\circ}$ corrugation angle. Two slits and one rectangular vortex generators having $1.3 \mathrm{~mm}$ width were additionally formed at the front and rear end of the tube. The ratio of louver area to total fin area $\left(A_{\ell} / A_{f}\right)$ was 0.261 . The double corrugated louver fin had 24 louvers of $0.8 \mathrm{~mm}$ louver pitch, $35^{\circ}$ louver angle and $19^{\circ}$ corrugation angle. The ratio of louver area to fin area $\left(A_{l} / A_{f}\right)$ was 0.259 . The standard louver fin had seven louvers of $1.4 \mathrm{~mm}$ louver pitch and $24^{\circ}$ louver angle including a flow re-direction louver at the center of the fin. The $A_{l} / A_{f}$ was 0.335 .

For the single louver fin samples, the transverse tube pitch $\left(P_{t}\right)$ was $21.0 \mathrm{~mm}$, the longitudinal tube pitch $\left(P_{l}\right)$ was $18.2 \mathrm{~mm}$, and those were $21.0 \mathrm{~mm}$ and $21.65 \mathrm{~mm}$ for the double corrugated louver fin samples. Resulting $P_{l} / P_{t}$ was 0.87 for the single corrugation sample and 1.03 for the double corrugation sample. There values were significantly larger than that of the standard louver fin $\left(P_{l} / P_{t}=0.6\right)$. Large $P_{l} / P_{t}$ implies large fin surface area, which will be beneficial to heat transfer. However, increased fin area will decrease the fin efficiency. Thus, net advantage of increasing the surface area should be assessed considering the change of heat transfer coefficient, decrease of the fin efficiency, and increase of the pressure drop as well. One thing to be noted is that the tube diameter of the double corrugated louver fin samples was $7.94 \mathrm{~mm}$, whereas that of the single corrugated and the standard louver fin samples were $7.3 \mathrm{~mm}$. A micro-fin tube having 60 micro-fins with $0.12 \mathrm{~mm}$ fin height and 25 degree helix angle was used in the tube-side. The tube was circuited to cross-counter configuration with single inlet and outlet. 

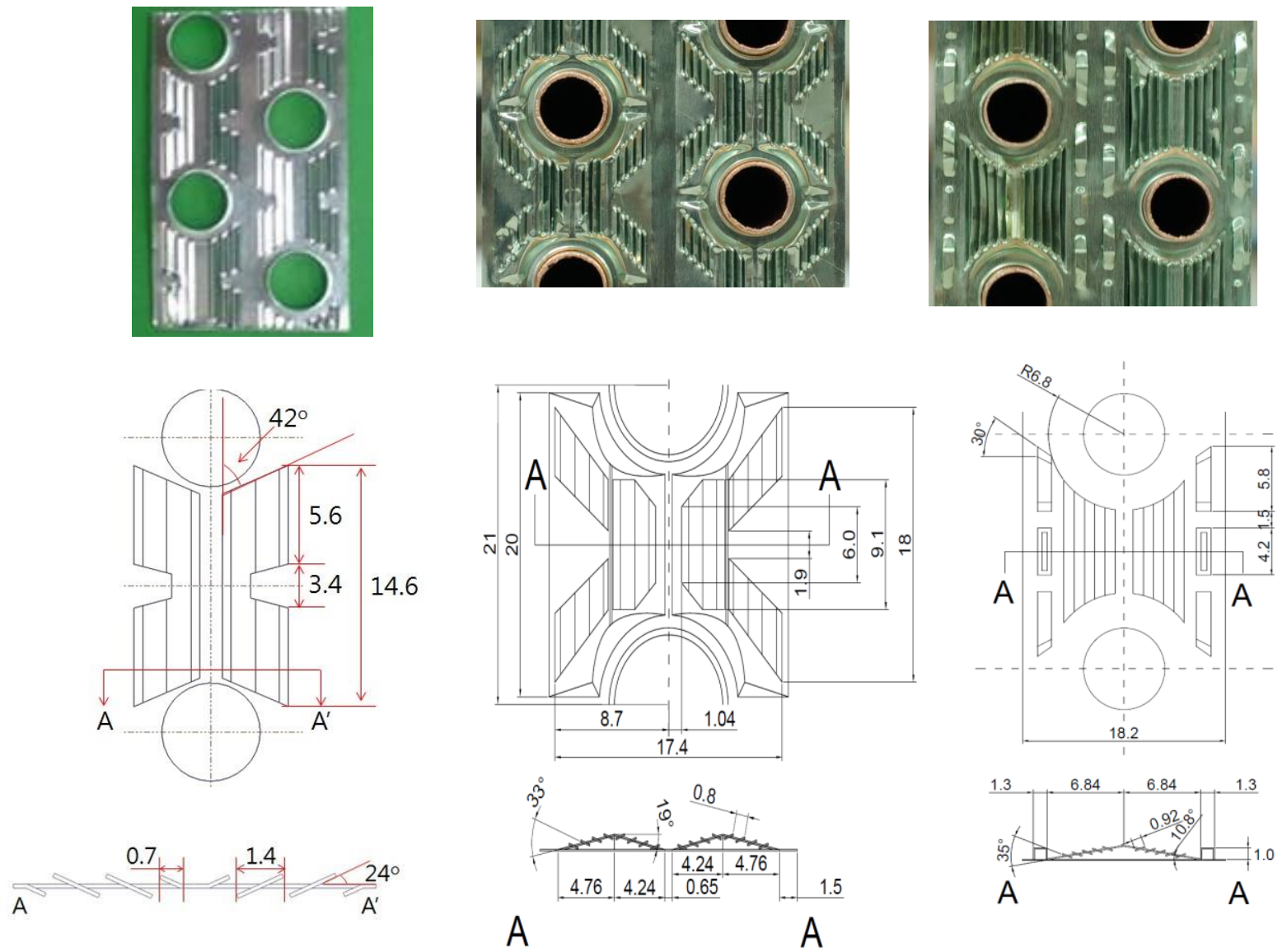

A

A

Fig. 2 Sketches and geometric dimensions of louver fin samples tested in this study

\subsection{Test apparatus and procedures}

The apparatus and the test procedure are described in detail in Kim and Cho (2015), and only a short summary is provided here. Tests were conducted in the apparatus shown in Fig. 3, which consisted of a suction-type wind tunnel and a water circulation unit. The apparatus was situated in a constant temperature and humidity chamber. The air temperatures were measured by the sampling method as suggested in ASHRAE Standard 41.1 (1986). The water temperatures were measured by

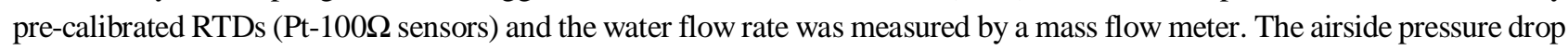
was measured using a differential pressure transducer, and the air flow rate was measured using a nozzle pressure difference according to ASHRAE Standard 41.2 (1987).

During the experiment, the water temperature was held at $45^{\circ} \mathrm{C}$ and the chamber temperature was maintained at $21^{\circ} \mathrm{C}$ with $60 \%$ relative humidity. Experiments were conducted varying the frontal air velocity from $0.5 \mathrm{~m} / \mathrm{s} \mathrm{to} 2.0 \mathrm{~m} / \mathrm{s}$. The energy balance between the airside and the tube-side was within $\pm 2 \%$ for most of the test range. It increased to $\pm 5 \%$ at the lowest velocity. An uncertainty analysis was conducted following ASHRAE Standard 41.5 (1975), and the results are listed in Table 3. The major uncertainty on the friction factor was the uncertainty of the differential pressure transducer $( \pm 10 \%)$, and the major uncertainty on the heat transfer coefficient (or $j$ factor) was that of the tube-side heat transfer coefficient $( \pm 10 \%)$. The uncertainties decreased as the airside Reynolds number increased. 
Table 2 Geometric dimensions of the test samples

\begin{tabular}{c|c|c|c|c|c|c|c|c|c|c|c|c}
\hline No. & $\begin{array}{c}\text { Fin } \\
\text { pattern }\end{array}$ & $\begin{array}{c}L_{p} \\
(\mathrm{~mm})\end{array}$ & $\begin{array}{c}\theta \\
(\mathrm{deg})\end{array}$ & $\begin{array}{c}\beta \\
(\mathrm{deg})\end{array}$ & $n_{l}$ & $A_{l} / A_{f}$ & $\begin{array}{c}P_{f} \\
(\mathrm{~mm})\end{array}$ & $\begin{array}{c}P_{t} \\
(\mathrm{~mm})\end{array}$ & $\begin{array}{c}P_{l} \\
(\mathrm{~mm})\end{array}$ & $P_{l} / P_{t}$ & $\begin{array}{c}D \\
(\mathrm{~mm})\end{array}$ & $N$ \\
\hline 1 & Single Corr. & 0.92 & 21.0 & 10.8 & 8 & 0.261 & 1.5 & 21.0 & 18.2 & 0.87 & 7.3 & 1 \\
\hline 2 & Single Corr. & 0.92 & 21.0 & 10.8 & 8 & 0.261 & 1.5 & 21.0 & 18.2 & 0.87 & 7.3 & 2 \\
\hline 3 & Single Corr. & 0.92 & 21.0 & 10.8 & 8 & 0.261 & 1.5 & 21.0 & 18.2 & 0.87 & 7.3 & 3 \\
\hline 4 & Single Corr. & 0.92 & 21.0 & 10.8 & 8 & 0.261 & 1.7 & 21.0 & 18.2 & 0.87 & 7.3 & 1 \\
\hline 5 & Single Corr. & 0.92 & 21.0 & 10.8 & 8 & 0.261 & 1.7 & 21.0 & 18.2 & 0.87 & 7.3 & 2 \\
\hline 6 & Single Corr. & 0.92 & 21.0 & 10.8 & 8 & 0.261 & 1.7 & 21.0 & 18.2 & 0.87 & 7.3 & 3 \\
\hline 7 & Double Corr. & 0.8 & 33.0 & 38.0 & 24 & 0.259 & 1.5 & 21.0 & 21.65 & 1.03 & 7.94 & 1 \\
\hline 8 & Double Corr. & 0.8 & 33.0 & 38.0 & 24 & 0.259 & 1.5 & 21.0 & 21.65 & 1.03 & 7.94 & 2 \\
\hline 9 & Double Corr. & 0.8 & 33.0 & 38.0 & 24 & 0.259 & 1.5 & 21.0 & 21.65 & 1.03 & 7.94 & 3 \\
\hline 10 & Double Corr. & 0.8 & 33.0 & 38.0 & 24 & 0.259 & 1.8 & 21.0 & 21.65 & 1.03 & 7.94 & 1 \\
\hline 11 & Double Corr. & 0.8 & 33.0 & 38.0 & 24 & 0.259 & 1.8 & 21.0 & 21.65 & 1.03 & 7.94 & 2 \\
\hline 12 & Double Corr. & 0.8 & 33.0 & 38.0 & 24 & 0.259 & 1.7 & 21.0 & 21.65 & 1.03 & 7.94 & 3 \\
\hline 13 & Std. Louver & 1.4 & 24 & - & 7 & 0.335 & 1.5 & 21.0 & 12.7 & 0.6 & 7.3 & 1 \\
\hline 14 & Std. Louver & 1.4 & 24 & - & 7 & 0.335 & 1.5 & 21.0 & 12.7 & 0.6 & 7.3 & 2 \\
\hline 15 & Std. Louver & 1.4 & 24 & - & 7 & 0.335 & 1.5 & 21.0 & 12.7 & 0.6 & 7.3 & 3 \\
\hline 16 & Plain & - & - & - & - & - & 1.5 & 21.0 & 12.7 & 0.6 & 7.3 & 1 \\
\hline 17 & Plain & - & - & - & - & - & 1.5 & 21.0 & 12.7 & 0.6 & 7.3 & 2 \\
\hline 18 & Plain & - & - & - & - & - & 1.5 & 21.0 & 12.7 & 0.6 & 7.3 & 3 \\
\hline
\end{tabular}

\subsection{Data reduction}

The data reduction details are also provided by Kim and Cho (2015), and a short summary is provided here. For the cross-counter configuration of the present study, appropriate equations for the heat exchanger analysis are given by ESDU 98005 (1998). The $U A$ value is obtained from the following equations.

$$
\begin{aligned}
& U A=C_{\min } N T U \\
& R=\min \left(C_{a}, C_{w}\right) / \max \left(C_{a}, C_{w}\right)
\end{aligned}
$$

The airside heat transfer coefficient under dry condition $\left(h_{o}\right)$ is obtained from the following equations. The heat transfer coefficient $\left(h_{o}\right)$ is based on total surface area $\left(A_{o}\right)$, which includes both the fin $\left(A_{f}\right)$ and the tube area $\left(A_{t}\right)$.

$$
\frac{1}{\eta_{o} h_{o} A_{o}}=\frac{1}{U A}-\frac{1}{h_{i} A_{i}}-\frac{1}{k A_{m}}
$$

For the tube-side heat transfer coefficients, Park et al. (1997) correlation, which was developed using the present 7.3 mm O.D. micro-fin tube, was used. The surface efficiency $\eta_{o}$ for use in Eq. (3) is obtained from Eq. (4).

$$
\eta_{o}=1-\frac{A_{f}}{A_{o}}(1-\eta)
$$

where the fin efficiency $\eta$ is given by Schmidt (1949). In the figures, heat transfer coefficients are presented as $j$ factors, and the flow velocities are presented as Reynolds numbers. 


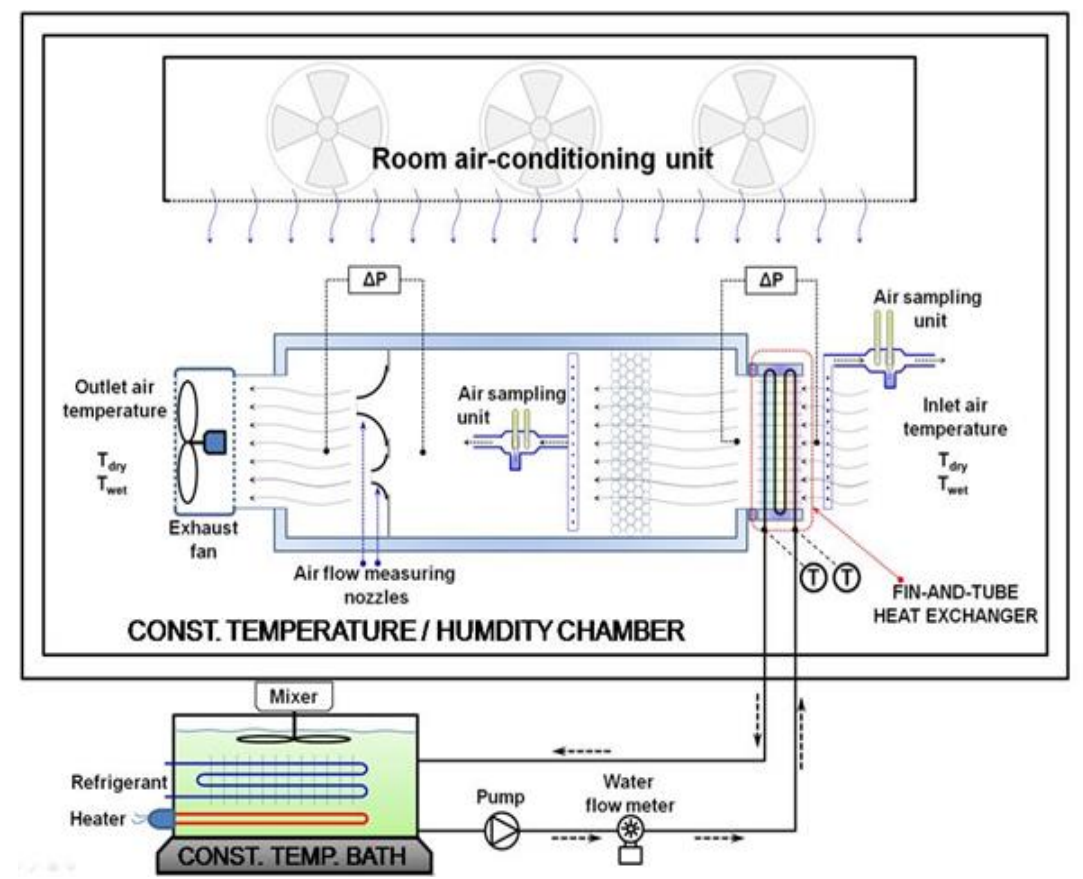

Fig. 3 Schematic drawing of the apparatus

Table 3 Estimated uncertainties

\begin{tabular}{c|c|c}
\hline Parameter & Range & $\begin{array}{c}\text { Max. } \\
\text { Uncertainties }\end{array}$ \\
\hline Air inlet temperature & $45^{\circ} \mathrm{C}$ & $\pm 0.1^{\circ} \mathrm{C}$ \\
\hline $\begin{array}{c}\text { Air outlet } \\
\text { temperature }\end{array}$ & $13 \sim 26^{\circ} \mathrm{C}$ & $\pm 0.1^{\circ} \mathrm{C}$ \\
\hline $\begin{array}{c}\text { Water inlet } \\
\text { temperature }\end{array}$ & $45^{\circ} \mathrm{C}$ & $\pm 0.1^{\circ} \mathrm{C}$ \\
\hline $\begin{array}{c}\text { Water outlet } \\
\text { temperature }\end{array}$ & $14 \sim 28^{\circ} \mathrm{C}$ & $\pm 0.1^{\circ} \mathrm{C}$ \\
\hline Differential Pressure & $5 \sim 100 \mathrm{~Pa}$ & $\pm 1.0 \mathrm{~Pa}$ \\
\hline Water flow rate & $0.064 \mathrm{~kg} / \mathrm{s}$ & $\pm 2.0 \%$ \\
\hline Re & $240 \sim 980$ & $\pm 2.0 \%$ \\
\hline$j$ & & $\pm 12.3 \%$ \\
\hline$f$ & & $\pm 10.4 \%$
\end{tabular}

$$
\begin{aligned}
& \operatorname{Re}_{D}=\frac{\rho_{a} V_{\max } D}{\mu_{a}}=\frac{G D}{\mu_{a}} \\
& j=\frac{h_{o}}{\rho_{a} V_{\max } c_{p a}} \operatorname{Pr}_{a}^{2 / 3}
\end{aligned}
$$

The core friction factor $(f)$ is calculated from the measured pressure drop. The friction factor $(f)$ is based on total surface area $\left(A_{o}\right)$, which includes both the fin $\left(A_{f}\right)$ and the tube area $\left(A_{t}\right)$.

$$
f=\frac{A_{c}}{A_{o}} \frac{\rho_{m}}{\rho_{\text {in }}}\left[\frac{2 \Delta P \rho_{\text {in }}}{\left(\rho_{m} V_{\max }\right)^{2}}-\left(1+\sigma^{2}\right)\left(\frac{\rho_{\text {in }}}{\rho_{\text {out }}}-1\right)\right]
$$




\section{Results and discussions}

Figures 4 and 5 show the effect of fin pitch on $j$ and $f$ factor of the single and the double corrugated louver fin samples. The figures show that, for the single corrugated louver samples, the effect of fin pitch on $j$ and $f$ factor is negligible. For the double corrugated inclined louver fin samples, however, $j$ factor increases as fin pitch increases. Furthermore, $j$ factor difference between $1.8 \mathrm{~mm}$ and $1.5 \mathrm{~mm}$ fin pitch sample becomes larger as number of tube row increases. As mentioned previously, existing investigations on standard louver fin samples show negligible effect of fin pitch on $j$ and $f$ factor [Wang et al. (1998a), Kim (2015)]. Then, why the effect of fin pitch is apparent for the double corrugated louver fin samples, and not apparent for the single corrugated louver fin samples? The clue may be found from the difference in corrugation geometry. As illustrated in Fig. 2 , for the single corrugated samples, the corrugation angle is $10.8^{\circ}$, which yields the corrugation height of $1.30 \mathrm{~mm}$ at the corrugation pitch of $6.84 \mathrm{~mm}$ (corrugation height to pitch ratio of 0.26 ). The corrugation height to pitch ratio of the double corrugated samples is 0.36 (corrugation angle of $19^{\circ}$, corrugation height of $1.38 \mathrm{~mm}$, corrugation pitch of $4.76 \mathrm{~mm}$ ), which is larger than that of the single corrugated sample. The effect of fin pitch on $j$ factor has been investigated by Wang et al. (1998b) for the convex louver fin sample having double corrugations per row and corrugation height to pitch ratio of 0.30 (corrugation height of $1.32 \mathrm{~mm}$, corrugation pitch $4.76 \mathrm{~mm}$ ). Their results showed that $j$ factor increased as the fin pitch increased, which is in line with the present results. Considering that the effect of fin pitch on $j$ factor is negligible for standard louver fin samples (having zero corrugation angle), it appears that, as the corrugation angle increases, the effect of fin pitch on $j$ factor becomes manifested. Of course, louver angle, louver pitch in addition to the corrugation angle will also affect the $j$ factor trend.

In Figs. 6 and 7, the effect of number of tube row is shown for the single and the double corrugated louver fin samples. For both configurations, the effect of number of tube row on $j$ factor is significant. The $j$ factor decreases as number of tube row increases. However, the effect of number of tube row on $f$ factor is negligible. These trends are commonly observed in fin-and-tube heat exchangers including louver fin samples [Wang et al. (1998a), Hsieh and Jang (2012)]. One thing to be noted is that, for single corrugated configuration, the $j$ factors of the two row and three row samples are almost identical, whereas the $j$ factors of three row sample are smaller than those of two row sample for double corrugated configuration. In general, the row effect weakens as the number of tube row increases, and eventually vanishes after three or four row [Webb and Kim (2005)]. Clearly, the weakening is more rapid for the single corrugated configuration than the double corrugated configuration.

In Fig. 8, $j$ and $f$ factors of the present samples are compared with those of the standard louver and the plain fin samples (Kim, 2015). Table 2 shows that the common fin pitch of all the samples is $1.5 \mathrm{~mm}$, and the comparison is made at that fin pitch. Figure 8 shows that the highest $j$ and $f$ factor were obtained for the standard louver fin sample, followed by the single corrugated louver fin, the double corrugated louver fin and then the plain fin sample.

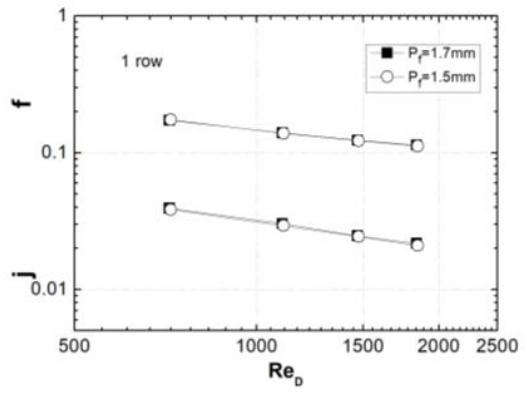

(a) 1 row

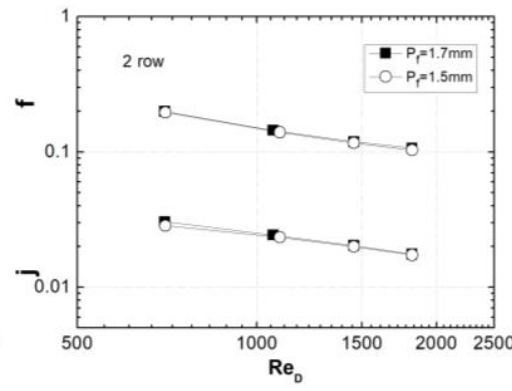

(b) 2 row

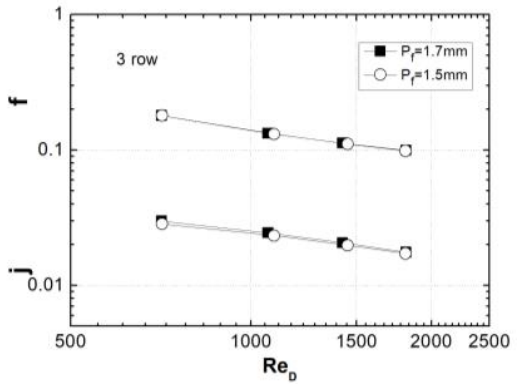

(c) 3 row

Fig. 4 Effect of fin pitch on $j$ and $f$ factor of the single corrugated louver fin samples 


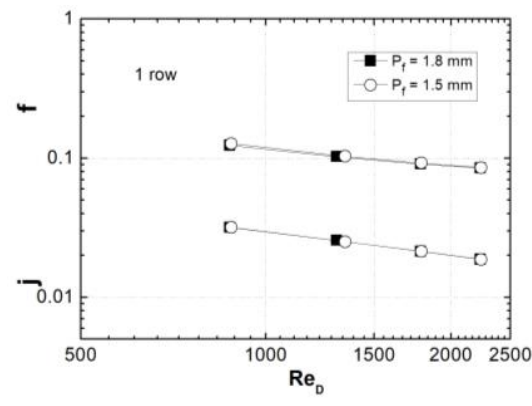

(a) 1 row

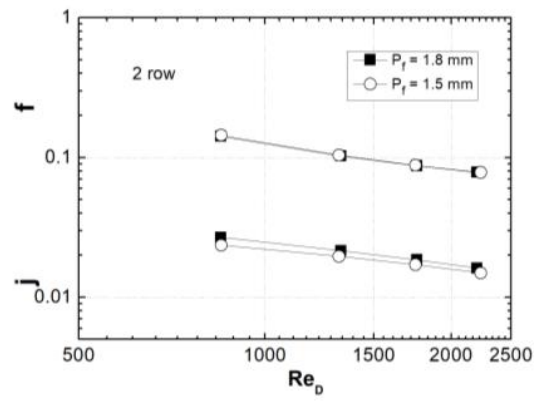

(b) 2 row

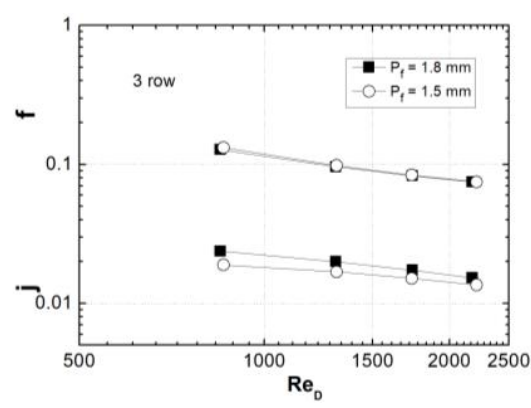

(c) 3 row

Fig. 5 Effect of fin pitch on $j$ and $f$ factor of the double corrugated louver fin samples

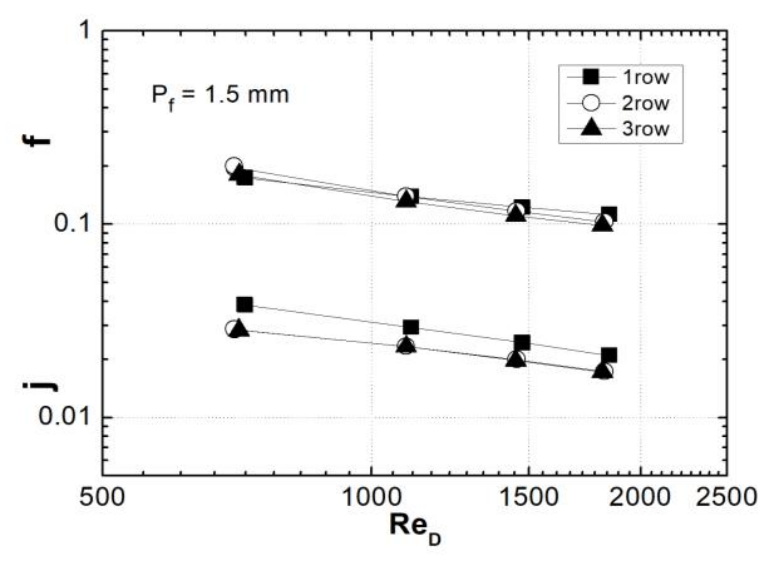

(a) $P_{f}=1.5 \mathrm{~mm}$

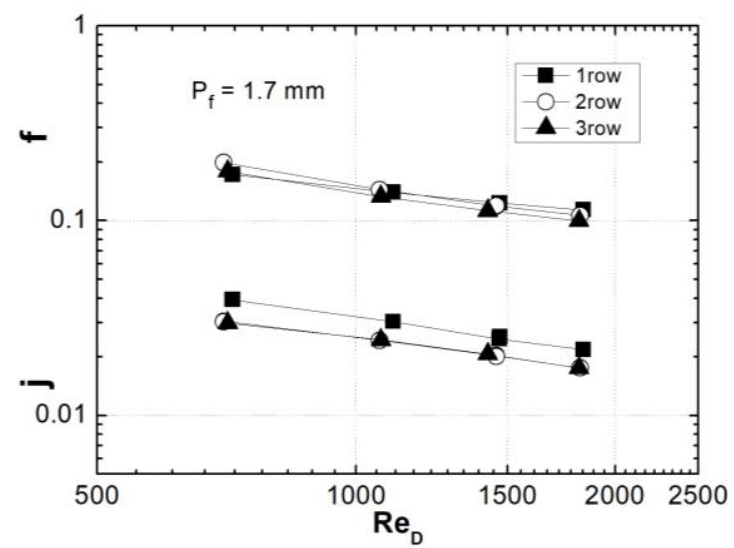

(b) $P_{f}=1.7 \mathrm{~mm}$

Fig. 6 Effect of number of tube row on $j$ and $f$ factor of the single corrugated louver fin samples

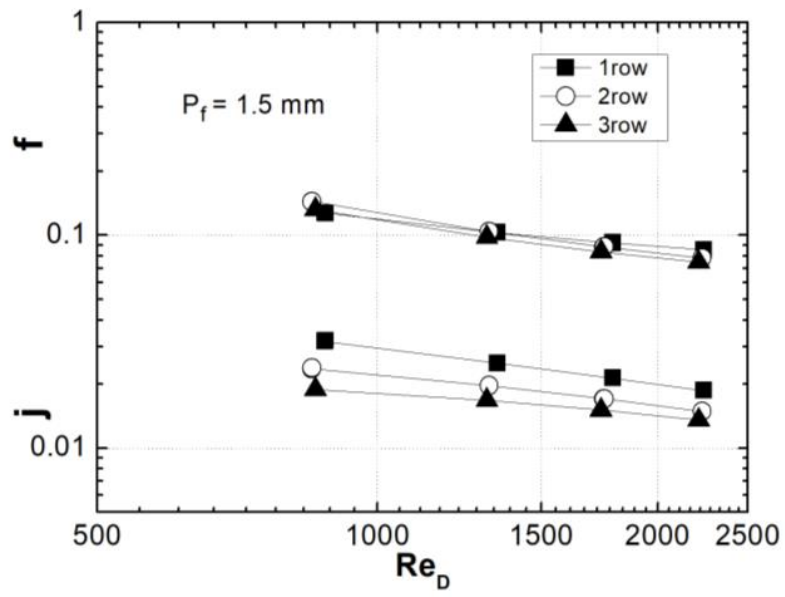

(a) $P_{f}=1.5 \mathrm{~mm}$

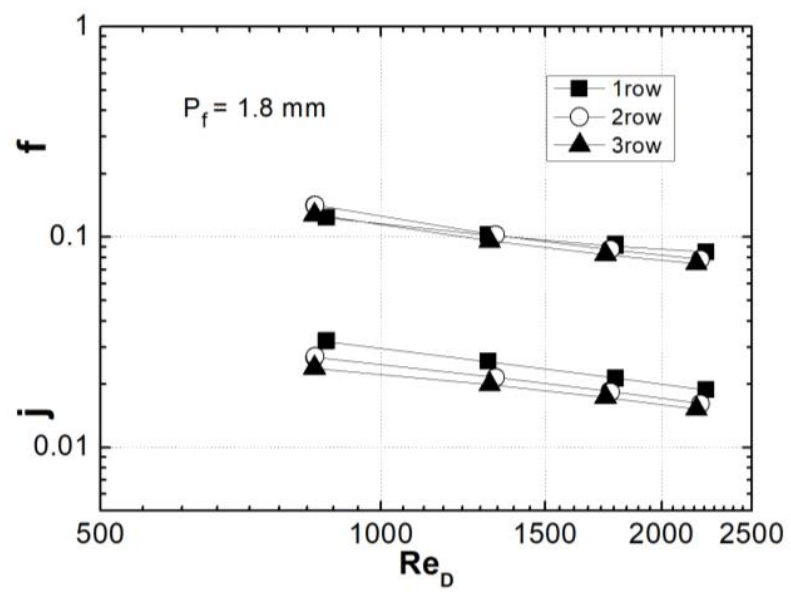

(b) $P_{f}=1.7 \mathrm{~mm}$

Fig. 7 Effect of number of tube row on $j$ and $f$ factor of the double corrugated louver fin samples 


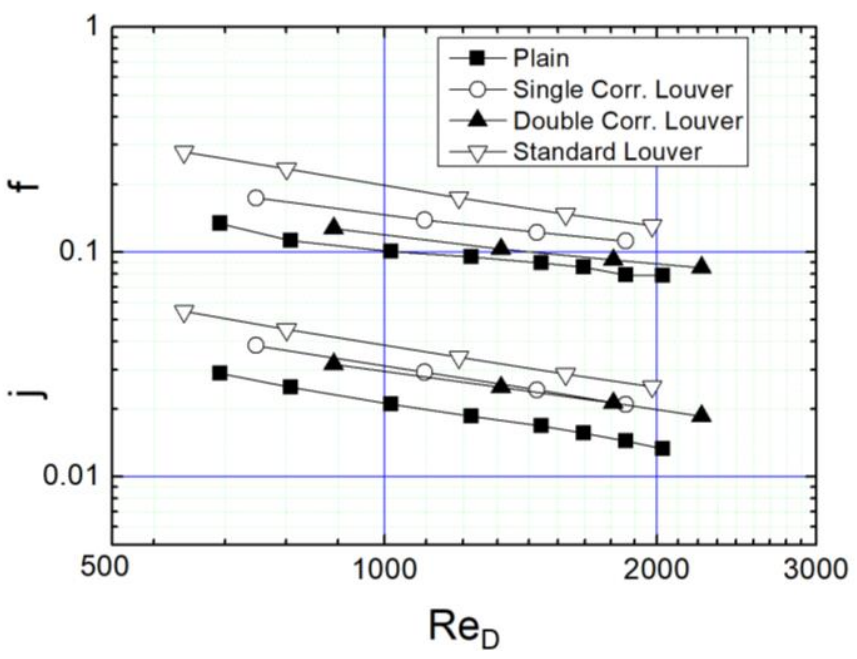

(a) 1 row

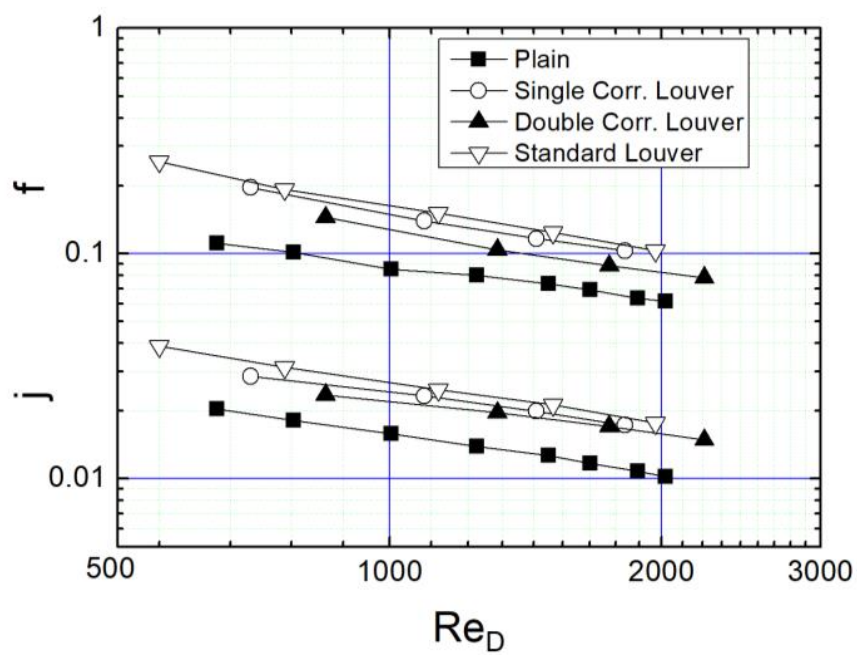

(b) 2 row

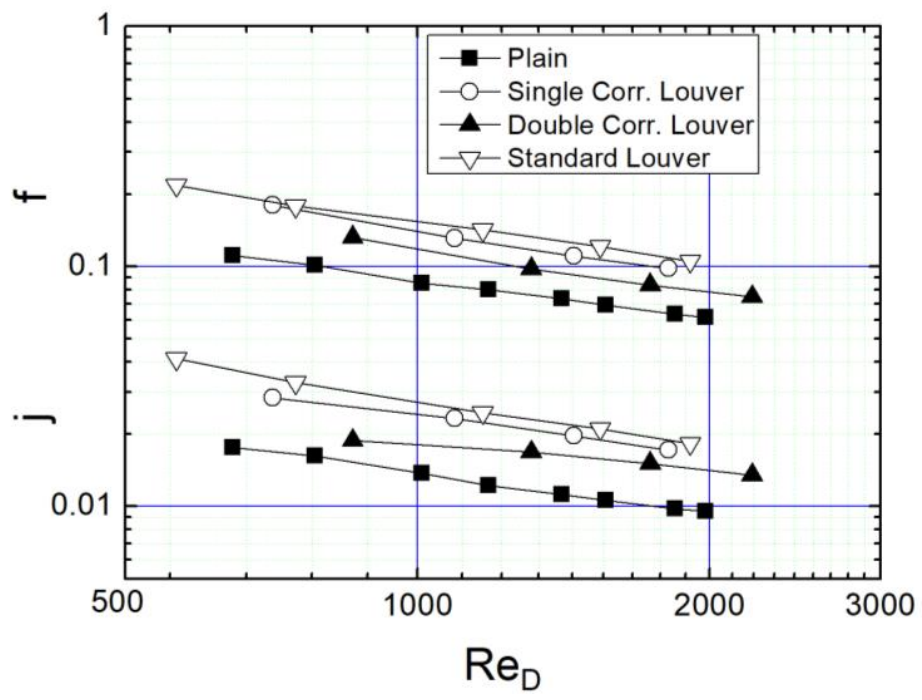

(c) 3 row

Fig. 8 Comparison of the $j$ and $f$ factors of the present samples with those of the standard louver and plain louver fin samples [Kim (2015)] at $P_{f}=1.5 \mathrm{~mm}$ 

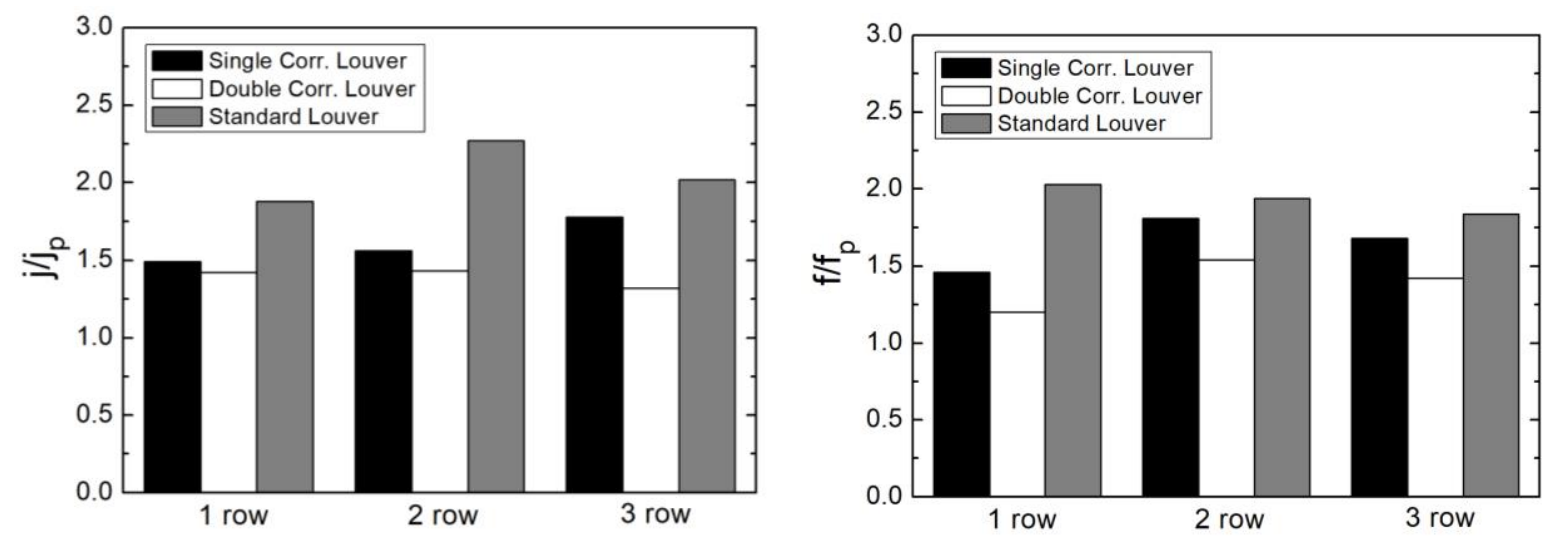

Fig. 9 Comparison of $j / j_{p}$ and $f / f_{p}$ at $\operatorname{Re}_{\mathrm{D}}=1000$

In Fig. 9, heat transfer enhancement factors $\left(j / j_{p}\right)$ and pressure drop penalty factors $\left(f / f_{p}\right)$ are compared. The factors were obtained from Fig. 8 by dividing the $j$ and $f$ factor of the enhanced fin samples by those of the plain fin sample at $\operatorname{Re}_{\mathrm{D}}=1000$. Considering that $j$ and $f$ curves are relatively parallel one another, the factors obtained at $\operatorname{Re}_{\mathrm{D}}=1000$ may represent those of the entire Reynolds number. Figure 9 shows that the trends are similar irrespective of the number of tube row. The highest factors were obtained for the standard louver fin sample, followed by the single corrugated louver fin and the double corrugated louver fin sample. To be specific, $j / j_{p}$ of the single corrugated louver fin samples are $1.49,1.56,1.78$ and the $f / f_{p}$ are $1.46,1.81,1.68$ for one row, two row and three row configuration respectively. For the double corrugated louver fin samples, the factors are $1.42,1.43,1.32$ for $j / j_{p}$ and $120,1.54,1.42$ for $f / f_{p}$. For the standard louver fin samples, the factors increase to $1.88,2.27,2.02$ for $j / j_{p}$ and $2.03,1.94,1.84$ for $f / f_{p}$.

Then, how the difference can be explained? For louver fin, the fin having more louver area will yield larger $j$ and $f$ factor. As listed in Table 2, the louver area to fin area $\left(A_{l} / A_{f}\right)$ is 0.335 for standard louver fin, 0.261 for single corrugated inclined louver fin and 0.259 for double corrugated louver fin. The high $j$ and $f$ factor of the standard louver fin may mainly due to the large $A_{l} / A_{f}$. Of course, other geometric parameters, especially louver pitch and louver angle, will affect the thermal performance of louver fin. In general, $j$ and $f$ factor increase as louver pitch decreases or louver angle increases. Table 2 shows that, between single and double corrugated inclined louver fins, the louver area to fin area ratio $(0.261$ vs. 0.259$)$, louver pitch $(0.8 \mathrm{~mm}$ vs. $0.92 \mathrm{~mm})$ and louver angle $\left(35^{\circ}\right.$ vs. $\left.33^{\circ}\right)$ are approximately the same. However, Fig. 9 shows that $j$ and $f$ factors are larger for the single corrugated louver fin sample. One point missing in the above discussion is the fin area. The above argument holds if the surface area of both fins is equal. However, the double corrugated fin has $22 \%$ more surface area than single corrugated fin. In general, local heat transfer coefficients and friction factors are large near the tube wall, and decrease away from the wall (Webb and Kim, 2005). Then, the fin having larger fin area will yield smaller $j$ and $f$ factor.

A performance evaluation criterion for a fin-and-tube heat exchanger has been proposed by Shah (1978), which is applicable to the case of different surface area. The criterion compares heat transfer capacity per volume $\left(\eta_{o} h_{o} A_{\delta} / V\right)$ and pumping power per volume $(P / V)$, which is readily obtained from the experimental $j$ and $f$ factors using the following relationship.

$$
\begin{aligned}
& \frac{\eta_{o} h_{o} A_{o}}{V}=\frac{4 \sigma c_{p}}{\operatorname{Pr}^{2 / 3}} \frac{j G}{D_{h}} \\
& \frac{P}{V}=\frac{2 \sigma}{\rho^{2}} \frac{f G^{3}}{D_{h}}
\end{aligned}
$$


In the equations above, $D_{h}$ is the hydraulic diameter, which is readily obtained from $D_{h}=4 L A_{c} / A$. In Figure 10 , $\eta_{o} h_{o} A_{\delta} / V$ are drawn as a function of $P / V$ using the $j$ and $f$ factors of Fig. 8. Figure 10 shows that enhanced fin samples yield larger heat transfer capacity than the plain fin samples at the same pumping power. Furthermore, the largest heat transfer capacity per pumping power is obtained for the standard louver fin sample. The single corrugated louver fin samples yield higher heat transfer capacity per pumping power than the double corrugated samples, and the difference increases as number of tube row increases. Then, what is the advantage of the present corrugated louver fins over the standard louver fin? The advantage is under wet condition. Under wet condition, the condensed water should be drained smoothly along the fin surface not blocking the passage between louvers. It appears that the corrugations are beneficial for the condensate drainage. This issue will be discussed in the companion paper (Kim, 2020).

As noted in the Introduction, T'Jeon et al. (2006) successfully predicted their inclined louver fin $j$ and $f$ data with convex louver fin correlation by Wang et al. (1998b). Thus, it was attempted to correlate the present inclined louver fin data with the correlation shown below.

$$
\begin{aligned}
& j=16.06 \operatorname{Re}_{D}^{-1.02\left(P_{f} / D\right)-0.256}\left(A_{o} / A_{t}\right)^{-0.601} N^{-0.069}\left(P_{f} / D\right)^{0.84} \\
& f=0.768\left[0.0494+0.142 \exp \left(-\operatorname{Re}_{D} / 1180\right)\right]\left(A_{o} / A_{t}\right)^{0.0195}\left(P_{f} / D\right)^{-0.121}
\end{aligned}
$$

Note that Wang et al. (1998b) correlation does not contain any louver parameter in it. Both single and double corrugated inclined louver fin data are compared with the predictions by the correlation, and the results are shown in Fig. 11. Figure 11 shows that reasonable prediction of the data is achieved by the correlation, especially for those of the double louver samples, where $79 \%$ of $j$ factors and $100 \%$ of $f$ factors are predicted within $\pm 20 \%$. For single inclined louver fin samples, $j$ factors are excellently predicted $(92 \%$ within $\pm 20 \%)$. However, only $8 \%$ of $f$ factors are within $\pm 20 \%$.

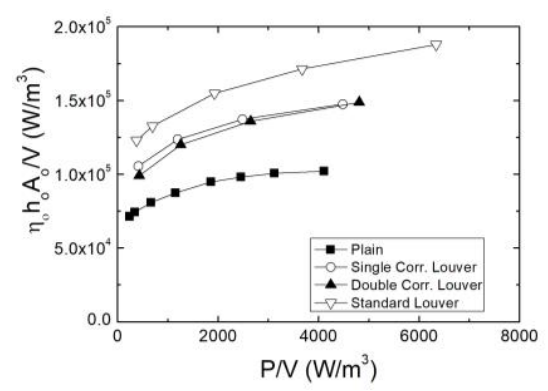

(a) 1 row

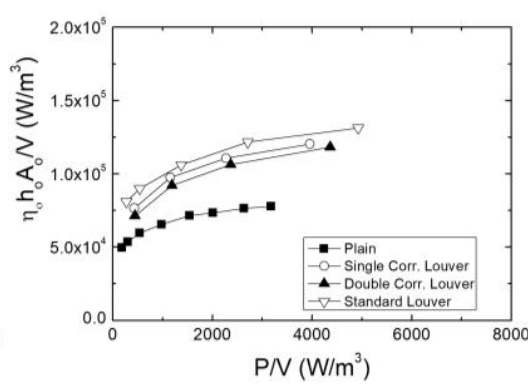

(b) 2 row

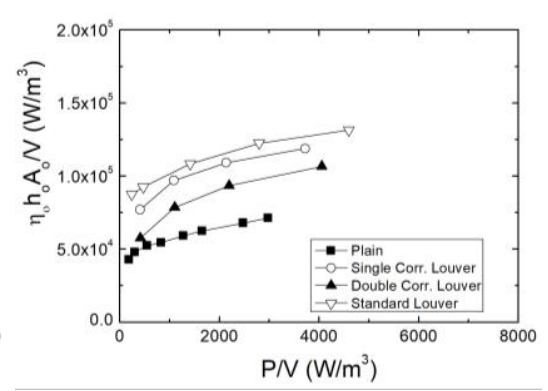

(c) 3 row

Fig. 10 Comparison of the heat transfer capacity per pumping power of the present samples with those of the standard louver and plain fin samples 


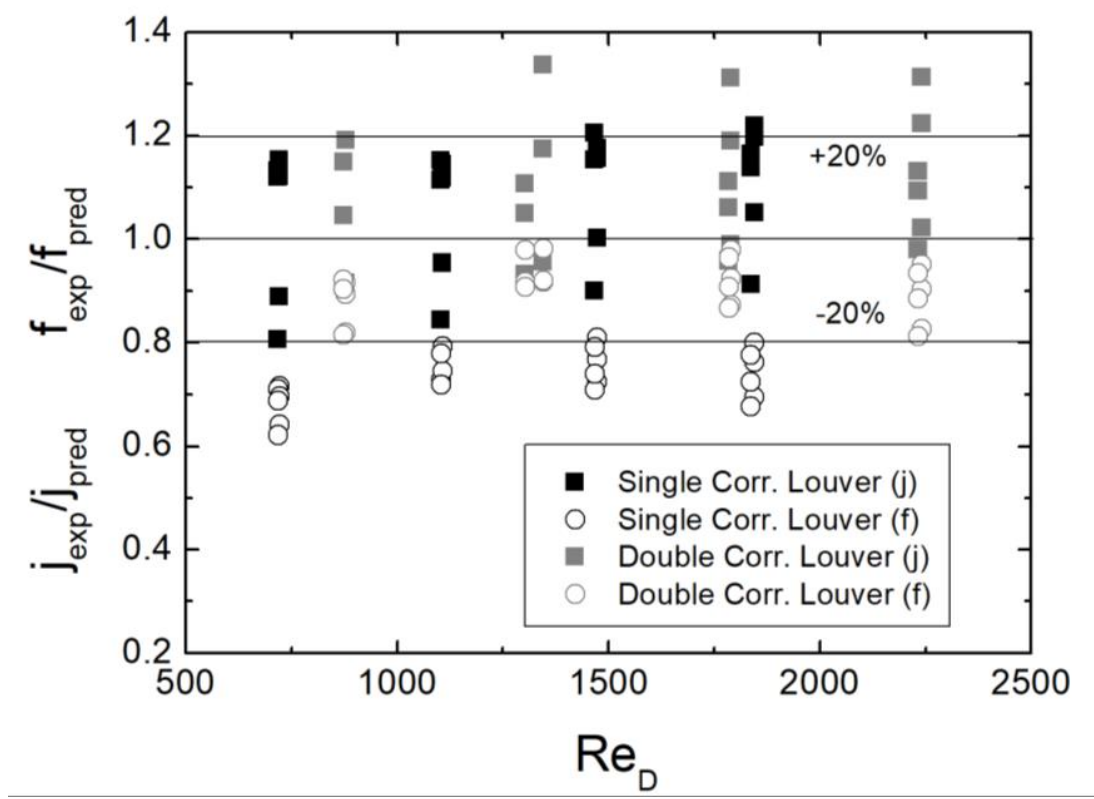

Fig. 11 Comparison of the present inclined louver fin sample $j$ and $f$ factors compared with predictions by Wang et al. (1998b)

\section{Conclusions}

In this study, two kinds of corrugated louver fin-and-tube heat exchangers - one having one corrugation per row and the other having two corrugations per row - were tested, and the results were compared with those of the standard louver fin and the plain fin samples. Listed below are major findings.

1) The highest $j$ and $f$ factor were obtained for the standard louver fin sample, followed by the single corrugated inclined louver fin, the double corrugated louver fin and then the plain fin sample.

2) The high $j$ and $f$ factor of the standard louver fin sample may be due to the large louver fraction of the fin area. Larger fin surface area of the double corrugated louver fin compared with that of the single corrugated louver fin may be the reason for the smaller $j$ and $f$ factor.

3) At $\operatorname{Re}_{\mathrm{D}}=1000$, the heat transfer enhancement factors $\left(j / j_{p}\right)$ of the single corrugated inclined louver fin samples were $1.49,1.56,1.78$ and the pressure drop penalty factors $\left(f / f_{p}\right)$ were $1.46,1.81,1.68$ for one row, two row and three row configuration respectively. For the double corrugated inclined louver fin samples, the factors were 1.42, $1.43,1.32$ for $j / j_{p}$ and $120,1.54,1.42$ for $f / f_{p}$. For standard louver fin samples, those increased to 1.88, $2.27,2.02$ for $j / j_{p}$ and $2.03,1.94,1.84$ for $f / f_{p}$.

4) All the enhanced fin samples yielded larger heat transfer capacity than the plain fin samples at the same pumping power. Furthermore, the largest heat transfer capacity per pumping power was obtained for the standard louver fin sample. The single corrugated inclined louver fin samples yielded higher heat transfer capacity per pumping power than the double corrugated samples.

\section{References}

ASHRAE Standard 41.1,Standard Method for Temperature Measurement, ASHRAE (1986). ASHRAE Standard 41.2, Standard Method for Laboratory Air-Flow Measurement, ASHRAE (1987).

ASHRAE Standard 41.5, Standard Measurement Guide, Engineering Analysis of Experimental Data, ASHRAE (1975). Carija, Z., Francovic, B. Percic, M. and Cavrak, M., Heat transfer analysis of fin-and-tube heat exchangers with flat and louvered fin geometries, Int. J. Ref., Vol. 45 (2014) pp. 160-167.

ESDU 98005, Design and Performance Evaluation of Heat Exchangers: the Effectiveness and NTU method, Engineering and Sciences Data Unit 98005 with Amendment A, London ESDU International plc. (1998), pp. 
122-129.

Hsieh, C.-T. and Jang, Y.-J., Parametric study and optimization of louver-finned heat exchangers by Taguchi method, Applied Thermal Eng., Vol. 42 (2012) pp. 101-110.

Kim, N.-H. and Cho, H., An experimental investigation of the airside performance of fin-and-tube heat exchangers having slit fins, J. Enhanced Heat Trans., Vol. 22, No. 1 (2015) pp. 67-88.

Kim, N.-H., An experimental investigation on the airside performance of fin-and-tube heat exchangers having corrugated louver fins - PartII; wet surface, submitted to J. Thermal Sci. Tech. (2020)

Park, B.-B., You, S.-M., Yoon, B. and Yoo, K.-C., Experimental study of heat transfer and pressure drop characteristics for flow of water inside circular smooth and micro-fin tubes, Korean J. Air Cond. Refrig., Vol. 9, No. 4 (1997), pp. $454-461$.

Saiz Jarbardo, J. M., Bastos Zoghbi Filho, J. R. and Salamanca, A., Experimental study of the air side performance of louver and wave fin-and-tube coils, Exp. Thermal Fluid Sci., Vol. 30 (2006) pp. 621-631.

Sadeghianjahromi, A., Kheradmand, S. and Nemati, H., Developed correlations for heat transfer and flow friction characteristics of louvered finned tube heat exchangers, Int. J. Thermal Sci., Vol. 129 (2018) 135-144.

Schmidt, T. E., Heat transfer calculations for extended surfaces, J. of ASRE, Refrigeration Engineering, Vol. 4 (1949), pp. 351-357.

Shah, R. K., Compact heat exchanger surface selection methods, Proc. $5^{\text {th }}$ Int. Heat Transfer Conf., Vol. 4 (1978) pp. 193-199.

T'Jeon, C., Steeman, H.-J., Wilcokx, A. and De Paepe, M., Determination of heat transfer and friction characteristics of an adapted inclined louver fin, Exp. Thermal Fluid Sci., Vol. 30 (2006) pp. 319-327.

Wang, C.-C., On the airside performance of fin-and-tube heat exchangers, in Heat Transfer Enhancement of Heat Exchangers, Eds. S. Kakac, A. E. Bergles, F. Mayinger, H. Yuncu (1999), p. 141, Kluwer Academic Press.

Wang, C.-C., Chi, K.-Y. and Chang, Y.-J., An experimental study of heat transfer and friction characteristics of typical louver fin-and-tube heat exchangers, Int. J. Heat Mass Transfer, Vol. 41, Nos. 4-5 (1998a) pp. 817-822.

Wang., C.-C., Tsai, Y.-M. and Lu, D.-C., Comprehensive study of convex-louver and wavy fin-and-tube heat exchangers, J. Thermophysics Heat Trans., Vol. 12, No. 3 (1998b) pp. 423-430.

Wang, C.-C., Lee, C.-J., Chang, C.-T. and Lin, S.-P., Heat transfer and friction correlation for compact louvered fin-and-tube heat exchangers, Int. J. Heat Mass Transfer, Vol. 42 (1999) pp. 1945-1956.

Webb, R. L. and Kim, N.-H., Principles of Enhanced Heat Transfer, 2nd Ed. (2005), Taylor and Francis Pub. 